\title{
O ensino de Física moderna e contemporânea na percepção dos professores da rede
} pública de Sobral

Modern and contemporary Physics teaching in the perception of Sobral public network teachers

Enseñanza de Física moderna y contemporánea en la percepción de profesores de la red pública Sobral

Recebido: 20/05/2020 | Revisado: 22/05/2020 | Aceito: 27/05/2020 | Publicado: 09/06/2020

Jonas Guimarães Paulo Neto

ORCID: https://orcid.org/0000-0002-4589-5413 Instituto Federal do Ceará - Campus Sobral, Brasil

E-mail: jonasgui1@ hotmail.com

Nórlia Nabuco Parente

ORCID: https://orcid.org/0000-0003-0910-8918 Instituto Federal do Ceará - Campus Sobral, Brasil

E-mail: norliapibid@gmail.com

Diego Ximenes Macedo

ORCID: https://orcid.org/0000-0001-9927-5546 Instituto Federal do Ceará - Campus Crateús, Brasil E-mail: diego.macedo@ifce.edu.br

\section{Resumo}

Desde o final do século XX, tem-se discutido acerca da inserção da Física Moderna e Contemporânea (FMC) na Educação Básica. Considerando o panorama atual de discussões sobre a necessidade de que esses assuntos estejam presentes no cotidiano escolar, mais precisamente do Ensino Médio (EM), esta pesquisa tem como objetivo investigar as concepções dos professores de Física das escolas públicas de Sobral acerca do ensino da FMC em suas aulas no EM. Para tanto, foi aplicado um questionário semiestruturado a todos os professores de Física das escolas públicas de Sobral que concluíram sua graduação após 2002. Observou-se que o tempo, o currículo desse nível e a ausência desses temas nos vestibulares são os principais empecilhos apontados pelos docentes para lecioná-los e que $67 \%$ afirmam 
inserir FMC em suas aulas, bem como chamam atenção para a necessidade de novas metodologias para o ensino desses conteúdos no EM e $47 \%$ tiveram dificuldades nesses assuntos durante sua formação.

Palavras-chave: Física moderna e contemporânea; Ensino Médio; Escolas públicas; Sobral; Ensino.

\begin{abstract}
Since the late twentieth century, there has been discussion about the insertion of Modern and Contemporary Physics (MCP) in Basic Education. Considering the current panorama of discussions about the need for these subjects to be present in everyday school life, more precisely in high school (HS), this research aims to investigate the conceptions of physics teachers of Sobral public schools about the teaching of MCP in your HS classes. For this, a semi-structured questionnaire was applied to all physics teachers of the Sobral public schools who completed their graduation after 2002. It was observed that the time, the curriculum of this level and the absence of these subjects in the entrance exams are the main obstacles pointed out by the students. teachers to teach them and that $67 \%$ claim to insert MCP in their classes, as well as draw attention to the need for new methodologies for teaching these contents in HS and $47 \%$ had difficulties in these subjects during their training.
\end{abstract}

Keywords: Modern and contemporary physics; High School; Public schools; Sobral; Teaching.

\title{
Resumen
}

Desde finales del siglo $\mathrm{XX}$, se ha debatido sobre la inserción de la física moderna y contemporánea (FMC) en la educación básica. Teniendo en cuenta el panorama actual de las discusiones sobre la necesidad de que estos temas estén presentes en la vida diaria de la escuela, más precisamente en escuela secundaria (ES), esta investigación tiene como objetivo investigar las concepciones de los profesores de física de las escuelas públicas en Sobral sobre la enseñanza de FMC en tus clases de ES. Con este fin, se aplicó un cuestionario semiestructurado a todos los profesores de física de las escuelas públicas de Sobral que completaron su graduación después de 2002. Se observó que el currículo a este nivel y la ausencia de estas materias en los exámenes de ingreso son los principales obstáculos señalados por maestros para enseñarles y que el 67\% afirma insertar FMC en sus clases, así como llamar la atención sobre la necesidad de nuevas metodologías para enseñar estos contenidos en ES y el $47 \%$ tuvo dificultades en estas materias durante su capacitación. 
Palabras clave: Física moderna y contemporánea; Escuela Secundaria; Escuelas públicas; Sobral; Enseñanza.

\section{Introdução}

Tradicionalmente, a Física é dividida em três grandes partes de acordo com o seu desenvolvimento histórico. A primeira delas é a Física Clássica (FC), que compreende as teorias clássicas da Mecânica, Termodinâmica e do Eletromagnetismo. Em seguida, é sucedida pela Física Moderna (FM), que por sua vez originou-se das tentativas de explicar as assimetrias detectadas, no final do século XIX, entre as teorias clássicas da Mecânica e do Eletromagnetismo e entre este último e os resultados experimentais da Termodinâmica. Os pressupostos básicos da FM (Teoria Quântica da Radiação e da Matéria e as Teorias da Relatividade) surgem a partir dos trabalhos revolucionários de cientistas como Max Planck (1858 - 1947) e Albert Einstein (1879 - 1955). Por fim, vivenciamos a construção da chamada Física Contemporânea (FCO), que se desenvolve a partir dos fundamentos da FM e inclui, em seu campo de estudo, a investigação e a discussão de assuntos como nanotecnologia, computadores quânticos, bóson de Higgs, ondas gravitacionais, dentre outros. A FCO não possui um marco teórico formalizado como a FM. Atualmente, consideramos que a FCO se iniciou em cerca da década de 40 do século passado, assim, as próximas gerações também vivenciarão a FCO. Portanto, é uma "parte" da Física que é marcada pelo tempo em que a sociedade vive, contínua (Paulo Neto, Oliveira, \& Siqueira, 2019).

Os estudos acerca da introdução de conteúdos de Física Moderna e Contemporânea (FMC) no currículo do Ensino Médio (EM) tiveram início no fim do século passado e se justificam através da importância que esses temas têm para a formação básica dos estudantes, bem como as diversas aplicações que possuem na explicação dos fenômenos e das tecnologias atuais. Trabalhos como o de Terrazzan $(1992,1994)$ foram um dos pioneiros com essa temática.

As discussões nos documentos oficiais acerca dessa inserção iniciaram com as Orientações Educacionais Complementares aos Parâmetros Curriculares Nacionais (PCN) em 2002 quando questionam acerca da necessidade de introduzir FM no EM, defendendo que alguns aspectos dessa área são indispensáveis para permitir que os jovens adquiram uma compreensão mais abrangente sobre como a matéria se constitui, de modo que tenham contato com diferentes e novos materiais, cristais líquidos e lasers presentes nos utensílios 
tecnológicos, ou com o desenvolvimento da eletrônica, dos circuitos integrados e dos microprocessadores (Brasil, 2002).

Monteiro, Nardi \& Bastos Filho (2012, p. 3) ressaltam que "as recomendações dos pesquisadores e dos documentos oficiais para que a FMC seja introduzida na educação básica não assegura que a mencionada Física esteja sendo contemplada nos planos de ensino e trabalhada em sala de aula pelos professores", pois não são obrigatórios, e sim recomendados.

Consagradamente, o ensino de Física nas escolas segue as tendências aplicadas em outros países (Terrazzan, 1992), os quais também iniciaram os estudos para introduzir tópicos de FMC na Educação Básica. A FC é a parte dessa componente curricular que historicamente é ensinada nas escolas, também é reforçada pela sequência de livros didáticos, principal e mais acessível meio de ensino e aprendizagem. Oliveira, Vianna e Gerbassi (2007) acrescentam que,

O currículo obsoleto, desatualizado e descontextualizado representa um problema tanto para os professores quanto para os estudantes e torna a prática pedagógica, que normalmente se resume ao quadro de giz, monótona e desinteressante para os atores envolvidos nesse processo. Nesse sentido, pesquisas estão sendo realizadas a fim de desenvolver estratégias que possam promover a motivação e o diálogo nas aulas de ciências, especificamente nas de física. Uma das vertentes que tem se destacado é a introdução de tópicos de Física Moderna (FM) na grade curricular do ensino médio (EM) (Oliveira, Vianna \& Gerbassi, 2007, p. 447).

Os temas de FMC costumam ser apresentados no final dos livros, quando volumes únicos, ou no fim do volume 3, quando a coleção é disposta em três livros. Eventualmente, conhecimentos de FMC aparecem no decorrer dos capítulos dos livros, porém, possuem caráter apenas informativo, não se configurando como ensino desses conteúdos realmente. $\mathrm{O}$ principal problema de se apresentarem de fato no fim dos livros é o tempo, pois as escolas, geralmente, possuem apenas duas aulas semanais de Física, sendo pouco tempo até para a FC. Um argumento para que sejam incluídos efetivamente ao longo dos três anos no EM é que não há nenhum motivo que justifique serem ensinados no final do $3^{\circ}$ ano desse nível, pois vários tópicos podem ser inseridos de diversas formas ao longo dos conteúdos de FC, não sendo preciso esperar tanto. Outro ponto é o tempo, como mencionado, pois se forem ensinados desde o $1^{\circ}$ ano, serão realmente incluídos nas aulas, além de contribuir para a formação dos alunos.

Quando se fala de atualização curricular, é impossível não se discutir sobre a formação de professores, pois são esses sujeitos que a implementarão (Terrazzan, 1992). Dessa forma, 
mostra-se essencial formar sujeitos preparados para tal ação, onde se inclui discutir desde o início da graduação discussões acerca dessa problemática, bem como propostas de intervenção. Ferreira e Strieder (2012) defendem que

a problemática da inserção de conteúdos de Física Moderna perpassa a formação de uma consciência no professor principalmente em assegurá-lo de que existe a viabilidade de se ensinar algo diferenciado no ensino médio e após conquistar esta etapa educacional pode-se tratar do currículo no ambiente escolar como um meio de aprimoramento do ensino aprendizado (Ibidem, 2012, p. 6).

Além disso, é de grande utilidade ser estudado e debatido com os professores durante sua formação sobre como podem realizar a Transposição Didática, termo introduzido em por Michel Verret em 1975 e teorizado posteriormente por Yves Chevallard em 1982 no livro La Transposition Didatique. Segundo Siqueira e Pietrocola (2006),

a Transposição Didática analisa as transformações ocorridas no saber desde a sua origem, denominado Saber Sábio até às salas de aula, quando o conteúdo chega aos alunos pelo professor, chamado de Saber Ensinado. Mostrando que o processo de transposição do saber não é uma mera simplificação. Nesse processo, são previstas características relevantes e regras que o saber deverá apresentar para se tornar um saber que chegue aos livros e depois à sala de aula (Ibidem, 2006, p. 1).

Frente ao exposto, a pesquisa tem como objetivo analisar as concepções de professores de Física das escolas públicas da cidade de Sobral - CE que se formaram após o ano de 2002 acerca da inserção de conteúdos de FMC no EM. Nesta, considera-se questões como as opiniões docentes sobre as possibilidades de se ensinar tais temas nesse nível, se eles o fazem, se são aptos para tal, se são necessárias novas metodologias, se tiveram dificuldades com esses temas ainda na sua formação e quais temas já inseriram em suas aulas. Para tanto, foi aplicado um questionário semiestruturado aos 15 professores das 13 escolas que se encaixaram no perfil descrito.

\section{Metodologia}

A pesquisa caracteriza-se como quantitativa e qualitativa, pois ao passo que se buscou percentuais para as questões propostas, foi feita uma análise qualitativa dos resultados buscando trabalhos relacionados. Para Bogdan e Biken (1994), a pesquisa qualitativa apresenta cinco características, a saber: o ambiente natural é a fonte direta de dados, sendo o 
investigador o instrumento principal; tem caráter descritivo; o sujeito investigador em mais interesse pelo processo do que pelos resultados ou produtos; os dados tendem a ser analisados de forma indutiva; e o significado possui importância vital.

Segundo Fonseca (2002), devido às amostras da pesquisa quantitativa ser comumente grandes e consideradas representativas da população estudada, seus resultados são tomados como se constituíssem um retrato real de todo o público alvo da pesquisa. Centrada na objetividade e influenciada pelo positivismo, a pesquisa quantitativa considera que a realidade apenas pode ser entendida com suporte na análise de dados brutos, os quais são recolhidos com o auxílio de instrumentos padronizados e neutros, além de recorrer à linguagem matemática para descrever as causas de um fenômeno, as relações entre variáveis, etc. $\mathrm{O}$ autor acrescenta que "a utilização conjunta da pesquisa qualitativa e quantitativa permite recolher mais informações do que se poderia conseguir isoladamente" (Fonseca, 2002, p. 20).

A pesquisa ainda se configura como de campo, que segundo Ibid (2002), caracterizase pelas investigações onde se realiza a coleta de dados junto aos sujeitos e possui objetivos exploratórios e explicativos, à medida que é desenvolvida "com o objetivo de proporcionar visão geral, de tipo aproximativo, acerca de determinado fato" (Gil, 2008, p. 27), tem "como preocupação central identificar os fatores que determinam ou que contribuem para a ocorrência dos fenômenos" (Gil, 2008, p. 28).

O trabalho é centrado na problemática da inserção de tópicos de FMC no EM pelos professores de Física das escolas públicas na cidade de Sobral - CE. A escolha desse local deve-se ao fato de ser a cidade na qual os autores trabalham e desenvolvem suas pesquisas. Soma-se a isso, o importante papel que teve na comprovação da Teoria Geral da Relatividade de Einstein em 1919 e possui o maior IDEB (Índice de Desenvolvimento da Educação Básica) do país.

Foi feita uma pesquisa para saber quantas escolas públicas há na cidade e após isso o investigador se apresentou nas instituições para esclarecer sua pesquisa ao representante da escola, diretor e/ou coordenador, e ao professor da mencionada componente curricular. Após aceita a realização, ambos assinaram termos de autorização da pesquisa naquele estabelecimento escolar e que estavam cientes do caráter da pesquisa, bem como suas implicações. São 13 escolas públicas na cidade, localizadas no centro e em bairros periféricos. Dessas, três são profissionais, três são integrais e sete são regulares. O público atendido são alunos da própria cidade e, em sua maioria, de classe média ou baixa. Além disso, algumas escolas estão localizadas em bairros onde as condições das necessidades básicas são precárias e há influência ao uso de drogas. 
Foi feita previamente uma pesquisa bibliográfica acerca da data que os conteúdos de FMC passaram a fazer parte da grade curricular do EM, observando-se que tal implementação se deu com as Orientações Educacionais Complementares aos Parâmetros Curriculares Nacionais (PCN) em 2002. Dessa forma, a pesquisa centrou-se nos professores que concluíram sua graduação após esse ano, visando analisar as possíveis mudanças quanto ao objeto de pesquisa. Ao todo, são 16 professores de Física nas 13 escolas públicas da cidade de Sobral, todos licenciados. No entanto, um professor concluiu sua graduação antes de 2002. Dessa forma, participaram da pesquisa 15 professores. Outro ponto importante é que há duas escolas em que apenas um docente leciona a disciplina de Física, portanto, ele responderá apenas por uma instituição, sendo colhidos os termos de consentimento de 12 escolas do EM.

Visando uniformidade nas respostas, os dados foram coletados através da aplicação de um questionário semiestruturado aos professores participantes da pesquisa. Foi escolhido esse método considerando também o que Gil (2008) afirma acerca das vantagens quando se compara o questionário com a entrevista, pois ele "não expõe os pesquisados à influência das opiniões e do aspecto pessoal do entrevistado" (p.122). Define-se semiestruturado por possuir questões abertas e em algumas os professores poderem justificar suas respostas, não ficando completamente fechado. Para manter o anonimato dos sujeitos participantes, utilizou-se letras de $\mathrm{A}$ à $\mathrm{O}$ para citar os professores durante a análise de suas respostas. É importante ressaltar também que alguns professores optaram por não responder algumas perguntas. Dessa forma, os percentuais que aparecem ao longo dos resultados são com base no total de professores respondentes para cada questão. O Quadro 1 contém quais professores não responderam as respectivas questões.

Quadro 1: Professores não respondentes para cada questão do questionário.

\begin{tabular}{|c|c|}
\hline Questão & Professor(es) \\
\hline 1 & - \\
\hline 2 & B \\
\hline 3 & B \\
\hline 4 & - \\
\hline 5 & B \\
\hline 6 & - \\
\hline 7 & - \\
\hline 8 & - \\
\hline 9 & B \\
\hline 10 & - \\
\hline 11 & A \\
\hline 12 & A, B \\
\hline 13 & A, B, K \\
\hline 14 & A \\
\hline 15 & A, L \\
\hline
\end{tabular}

Fonte: Dados da Pesquisa, 2019. 
Research, Society and Development, v. 9, n. 7, e749974748, 2020

(CC BY 4.0) | ISSN 2525-3409 | DOI: http://dx.doi.org/10.33448/rsd-v9i7.4748

Nesse quadro é importante atentar que alguns professores não responderam algumas questões, de forma que os percentuais que aparecem na análise e discussão dos dados são referentes aos respondentes.

Para a análise dos questionários, foi realizada uma pesquisa na internet acerca dos principais trabalhos que tratam da abordagem de conteúdos de FMC no EM e foram feitas comparações, sempre que possível, com os resultados alcançados pelos autores em suas pesquisas, buscando verificar certa convergência ou divergência entre os dados. Algumas das principais pesquisas foram: Machado \& Nardi (2003); Oliveira, Vianna \& Gerbassi (2007); Monteiro \& Nardi (2009); Miltão \& Alves (2009); Monteiro, Nardi \& Bastos Filho (2009); e Monteiro, Nardi \& Bastos Filho (2012).

\section{Resultados e Discussão}

Apresenta-se a seguir as questões que constituíram o questionário semiestruturado aplicado aos 15 professores de Física das escolas públicas de Sobral participantes desta pesquisa, bem como é feita uma análise quantitativa e qualitativa dos dados baseando-se nas pesquisas com enfoque no ensino de tópicos de FMC no EM.

A primeira pergunta tinha como objetivo saber se os professores consideram possível lecionar FMC no EM. Oito professores responderam que sim e seis que parcialmente. $\mathrm{O}$ Quadro 2 contém as justificativas para suas respostas.

Quadro 2: Possibilidade de ensinar FMC no EM.

\begin{tabular}{|c|c|l|}
\hline Professor & Respostas & \multicolumn{1}{c|}{ Justificativas } \\
\hline A & Parcialmente & Alfabetização científica e informação sempre terão importância na formação de jovens \\
\hline B & Parcialmente & Apenas os conceitos qualitativos \\
\hline C & Parcialmente & Devido sua maturidade cognitiva \\
\hline D & Sim & São conceitos importantes \\
\hline E & Sim & Já faz parte dos parâmetros curriculares \\
\hline F & Sim & O aluno deve saber onde a Física já chegou e quais seus desafios \\
\hline G & Sim & São conteúdos atuais, chamam a atenção dos alunos \\
\hline H & Sim & Porque são temas atraentes, porém, em minha opinião devem ser tratados teoricamente \\
\hline I & Sim & Pois complementa o currículo, além de abordar assuntos importantes que insere o cotidiano \\
\hline J & Sim & Porque é um conteúdo voltado para as novas tecnologias e novas teorias \\
\hline K & Sim & Porque pode ser inserida igualmente aos outros assuntos de Física \\
\hline L & Parcialmente & A ausência de experimentos pode dificultar a absorção do conteúdo \\
\hline M & Parcialmente & $\begin{array}{l}\text { A grande dificuldade de se abordar estes conteúdos é o tempo, para explicação do mesmo } \\
\text { muitas vezes é necessário reorganizar o tempo. Além desse fator, acredito que a abordagem } \\
\text { do conteúdo é facilitada para alunos que já conhecem os conceitos de ondas e eletricidade } \\
\text { básica }\end{array}$ \\
\hline N & Parcialmente & Se tivéssemos um projeto que focasse mais na parte teórica e menos na prática \\
\hline
\end{tabular}

Fonte: Dados da Pesquisa, 2019. 
Por meio do Quadro 2 pode-se observar que todos os docentes consideram que é possível ensinar FMC no EM, mostrando que há, pelo menos, uma compreensão da possibilidade de que esses assuntos venham a ser comtemplados na Educação Básica. Pode-se perceber que os professores apresentam justificativas interessantes e que dão ainda mais ênfase para o ensino de FMC, como a importância que atribue, a presença nos documentos oficiais, a compreensão dos limites que são enfrentados hoje, a atualidade e atratividade inerente aos temas e as relações com o cotidiano. Para um professor participante da pesquisa de Rocha e Ricardo (2011), o fato de a FMC ser mais próxima da realidade dos alunos permite que os professores realizem uma abordagem mais contextualizada.

É interessante citar a fala do professor $\mathrm{K}$ quando atesta que a FMC pode ter o mesmo espaço que a FC nas aulas de Física, pois o que se observa hoje é que os conteúdos de FMC aparecem no fim do volume 3 das coleções didáticas, o qual nem sempre é possível se alcançar, contribuindo para que não seja ensinada. No entanto, ele enfatiza que se pode ensinar da mesma forma que são ensinados os outros conteúdos. Os professores E e I citam o currículo, e, sem dúvidas, esses assuntos contribuem significativamente com o currículo do EM e complementam a formação básica dos alunos. Entretanto, o fato de estarem presentes nos documentos oficiais não garante que estejam realmente sendo ensinados em sala de aula (Monteiro, Nardi, \& Bastos Filho, 2012).

Para os professores que responderam parcialmente, observa-se que apenas os conceitos qualitativos devem ser ensinados, pois a maturidade cognitiva dos alunos se mostra como um obstáculo. A ausência de experimentos, a necessidade de conhecimentos prévios e o tempo também são fatores importantes quando se trata do ensino de FMC no EM. Esses assuntos são conhecidos pelo seu aspecto matemático mais elevado e pela maior abstração, dessa forma, é preciso fazer readequações para torná-los plausíveis de serem lecionados nesse nível. Zanetic (2005) salienta que a perspectiva de o professor ensinar FMC com um foco restrito ao seu formalismo matemático impossibilita a construção de um ensino em sintonia com questões sociais mais amplas, além de também ser abordada em articulação com a cultura, como recomendam Carvalho e Zanetic (2004). Sobre a maturidade cognitiva citada pelo professor C, é interessante a fala de Ostermann e Moreira (2001) quando afirmam que

[...] é viável ensinar FMC no EM, tanto do ponto de vista do ensino de atitudes quanto de conceitos. É um engano dizer que os alunos não têm capacidade para aprender tópicos atuais. A questão é como abordar tais tópicos [...] Se houve dificuldades de aprendizagem não foram muito diferentes das usualmente enfrentadas com conteúdos da física clássica [...] Os alunos podem aprendê-la se os professores estiverem 
adequadamente preparados e se bons materiais didáticos estiverem disponíveis (Ostermann \& Moreira, 2001, p. 11).

Portanto, com base nesses resultados e nos autores citados, evidencia-se importante e torna-se mais didático que o ensino de FMC enfoque os aspectos conceitual, histórico e experimental, visto as limitações do nível médio, além de que a compreensão de fato dos assuntos possui mais significado para a formação dos alunos, podendo interligar ao seu dia a dia. Complementando os autores citados, uma aprendizagem significativa de FMC pode ser construída com uma formação adequada dos professores de Física e com a confecção de materiais que supram as necessidades docentes.

Nas pesquisas nessa área, os professores apontam que a falta de tempo é um fator que impede a abordagem dos temas de FMC, ou sua exploração mais extensiva, sendo esse um fator que pode influenciar a maioria dos docentes, tendo em conta a baixa carga horária que mencionaram destinar à FMC. Alegam também que a carga horária de Física não é suficiente nem para ensinar FC, considerando as dificuldades dos alunos e a extensa programação do currículo de Física. Além disso, citam ainda a desorientação por parte da direção escolar do que deve ser ensinado e a não exigência dessa Física nos programas de exames vestibulares, acarretando ausência da FMC em suas aulas (Ferreira \& Strieder, 2012; Machado \& Nardi, 2009; Monteiro, Nardi, \& Bastos Filho, 2009; Oliveira, Vianna, \& Gerbassi, 2007).

Ostermann \& Moreira (2001) reforçam que uma alternativa para superar esse problema seria uma restruturação curricular, além da ampliação da carga horária de Física. Desse modo, colocaria menos ênfase nos conceitos clássicos que não são essenciais e, maior ênfase nos tópicos de FMC. Acrescentam ainda que inserir os conceitos de FMC desde o início do EM mostra-se como outra saída, contrapondo a tradição de se esperar o final do $3^{\circ}$ ano para ensiná-los. Os livros didáticos de Física também devem ser reformulados, pois comumente trazem os tópicos de FMC no final, seja no último volume ou no final dos capítulos, isso quando abordam o assunto.

Em seguida, foi perguntado aos professores se eles inserem temas de FMC em suas aulas de Física do EM. Dez docentes afirmaram que sim e quatro afirmaram que não incluem esses assuntos em suas aulas. As justificativas para não inserir foram: "Sigo um currículo já estabelecido" (professor J); "Não vejo que seja necessário, pois o foco dos alunos e escolas da região são ENEM e vestibular, e em ambos não exige conhecimento do assunto em questão" (professor K); "Porque ficamos presos ao currículo educacional” (professor N). 
Observa-se que cerca de $70 \%$ dos docentes ensinam tópicos de FMC, corroborando a perspectiva de Ferreira \& Strieder (2012) quando afirmam que, considerando o crescimento tecnológico acentuado, é muito importante que os professores abordem a FMC no EM para que os alunos possam compreender e participar das transformações sociais e científicas vivenciadas no cotidiano. Machado \& Nardi (2003) observaram que 79\% dos professores lecionam algum tópico dessa área. Entretanto, apenas $29 \%$ dos professores informaram ensinar temas de FMC frequentemente, $38 \%$ às vezes, $8 \%$ raramente e $21 \%$ nunca. Em sua pesquisa, Busatto, Silva, Pansera Jr \& Pérez (2018) constataram que 35\% dos docentes entrevistados não inserem FMC em suas aulas.

Miltão \& Alves (2009) citam que é preciso programar múltiplas ações em conjunto para que se possam superar as dificuldades e inserir os conteúdos de FMC no EM. Salientam ainda que a responsabilidade por um ensino de qualidade não deve ser apenas dos professores, pois a culpa da defasagem de conteúdos não é, puramente, um problema dos professores, mas, também, das escolas. Portanto, deve ser realizado um trabalho de coordenação pedagógica para que se insira esses conteúdos em seus programas e procurar estratégias, junto aos docentes, para realizar um ensino de ciências com qualidade. Essa responsabilidade também precisa ser dividida entre as universidades, que vêm preparando de forma inadequada.

$\mathrm{O}$ professor $\mathrm{K}$ afirma ser possível inserir tópicos de FMC no EM, no entanto, não insere porque não considera necessário, já que não são cobrados no ENEM e nos vestibulares. Utilizando a justificativa do professor E para as possibilidades de lecionar esses assuntos, observa-se que mesmo que os documentos oficiais defendam essa prática, o currículo escolar tem caminhado em sentido oposto, pois não contêm esses conteúdos, limitando a atuação dos professores, já que é utilizado como elemento norteador. Sobre isso, é importante citar que sua desatualização do currículo acarreta prejuízos para a formação dos estudantes do EM, bem como o fato de os professores se sentirem presos a ele. Para Oliveira, Vianna e Gerbassi (2007),

a lacuna provocada por um currículo de física desatualizado resulta numa prática pedagógica desvinculada e descontextualizada da realidade do aluno. Isso não permite que ele compreenda qual a necessidade de se estudar essa disciplina que, na maioria dos casos, se resume em aulas baseadas em fórmulas e equações matemáticas, excluindo o papel histórico, cultural e social que a física desempenha no mundo em que vive (Oliveira, Vianna, \& Gerbassi, 2007, p. 448). 
$\mathrm{Na}$ terceira questão foi perguntado aos professores se se sentem aptos a lecionar FMC no EM. O Gráfico 1 mostra suas respostas. Caso respondessem não ou parcialmente, podiam justificar. O Quadro 3 traz suas justificativas.

Gráfico 1: Habilidade dos professores ensinarem FMC.

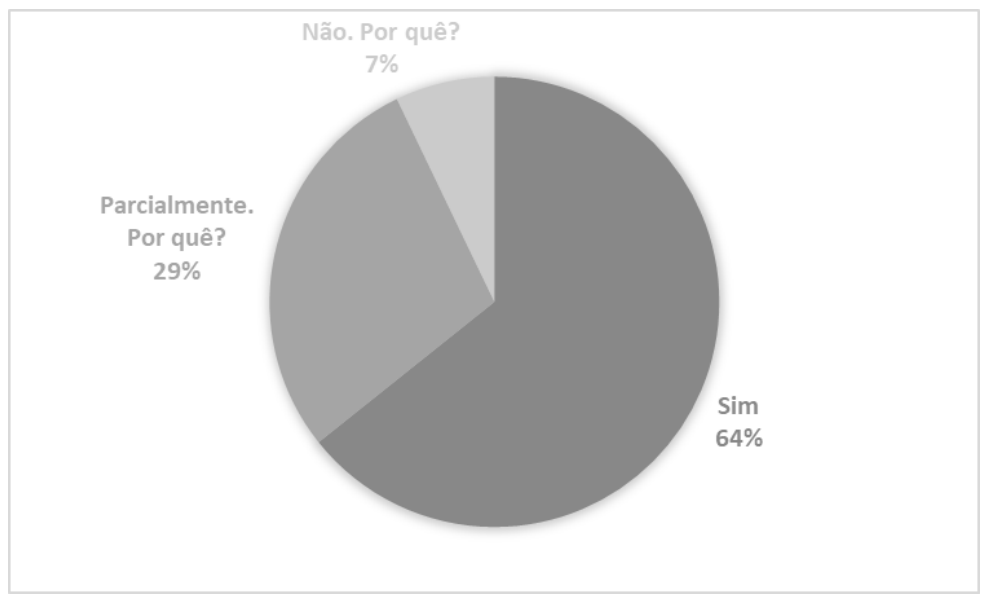

Fonte: Dados da Pesquisa, 2019.

Quadro 3: Justificativas para a não capacidade de ensinar FMC.

\begin{tabular}{|c|c|l|}
\hline Professor & Respostas & \multicolumn{1}{|c|}{ Justificativas } \\
\hline C & Parcialmente & Devido a metodologia \\
\hline E & Parcialmente & Tenho que aprimorar minha formação nesse campo \\
\hline H & Parcialmente & Porque não tive contato com todos os tópicos \\
\hline N & Não & $\begin{array}{l}\text { A realidade da escola pública no Ensino Médio é totalmente } \\
\text { diferente do que idealizamos na universidade }\end{array}$ \\
\hline
\end{tabular}

Fonte: Dados da Pesquisa, 2019.

Percebe-se que quase $40 \%$ dos professores ainda não se sentem completamente aptos a lecionar FMC no EM. Tal fato pode conduzi-los a, algumas vezes, não inserir esses temas nesse nível, devido às dificuldades que encontram. Os professores $\mathrm{H}$ e $\mathrm{E}$ afirmam que se sentem parcialmente apto devido não terem tido contato com todos os tópicos e haver necessidade de aprimorar sua formação, respectivamente, o que retrata as deficiências na formação de professores. Ferreira \& Strieder (2012), Monteiro, Nardi \& Bastos Filho (2009) e Rocha \& Ricardo (2011) observaram em suas pesquisas que os professores tiveram deficiências durante sua formação em FMC, culminando na impossibilidade de inserir esses temas em suas aulas. Para eles, esses conteúdos requerem um pouco mais de abstração e, 
contrariamente à FC, quando não se possui um conhecimento satisfatório, pode-se fazer um resumo dos livros didáticos. No entanto, isso não se aplica para a FMC. Os autores observaram falta de autonomia nos docentes entrevistados em introduzirem a FMC no EM e, dessa forma, implementar ações visando a autonomia dos estudantes, uma vez que por não dominarem o assunto, não o ensinavam, já que sua formação em FMC também foi deficiente, pautada na Matemática e temas muito abstratos. Chegam também a alegar a capacidade de ensinar esses temas apenas superficialmente, sendo sua formação em FMC o principal problema, e que apenas ensinariam tais assuntos se se atualizassem, pois não se encontravam preparados, evidenciando, conforme os autores, a insegurança dos professores e necessidade de formação continuada.

Miltão \& Alves (2009) ressaltam que é importante entender que o problema da formação de professores decorre de uma base deficiente e que isso vem desde o EM, sendo levado durante toda a sua graduação, sendo um problema é muito difícil de se resolver, mas não impossível. Precisa-se de políticas educacionais conscientes e responsáveis que priorizem a aprendizagem qualitativa.

Monteiro e Nardi (2009) constataram que o ensino de FMC durante a graduação de professores tem sido fortemente pautado na racionalidade técnica, que, segundo Camargo e Nardi (2005), também prevalecente no EM.

Nesta, os meios são planejados para atingir determinados fins, previamente estabelecidos e sem valorizar especificidades do contexto. Com um contexto da formação de professores pautada nesta racionalidade, os mesmos são preparados como sendo técnicos a resolverem problemas. Ao se depararem com o contexto educacional, os quais apresentam problemas de natureza causal complexa, muito frequentemente os professores que tiveram formação pautada na mencionada perspectiva, começam a perceber a inviabilidade do seu arcabouço teórico para fundamentar a sua práxis (Monteiro \& Nardi, 2009, p. 9).

Sobre isso, Rosa e Schnetzler (2003) atestam que estruturação do currículo nos cursos superiores demonstra outra influência da racionalidade técnica na formação de professores, pois geralmente é organizado em disciplinas chamadas de conteúdos específicos e disciplinas pedagógicas, as quais são trabalhadas com nenhuma relação entre si.

A quarta questão questionava aos professores que marcassem não na questão anterior se eles já buscaram formas de ensinar FMC no EM. O único docente que marcou afirma que não realizou buscas de como inserir esses tópicos nesse nível e acrescenta: "busco focar nos conteúdos que mais são cobrados nas avaliações externas" (professor N). Observa-se que os 
vestibulares, que são as avaliações externas citadas pelo professor mencionado, parecem nortear os conteúdos que são ensinados no EM, mostrando que o ensino de Física tem tomado como objetivo a aprovação dos alunos no vestibular, e não as questões relacionadas com a formação íntegra do ser crítico. O docente relata que durante a faculdade o EM é visto de uma forma e quando, chega em sala de aula verifica que a realidade é diferente, o que demonstra que a formação de professores parece não levar em consideração o contexto em que os professores em formação e os estudantes do EM estão inseridos. O mesmo docente relata que se houvessem projetos que focassem mais a teoria e menos os cálculos da FMC seria possível incluir no nível de ensino discutido. No entanto, afirma não inserir tais temas por estar preso ao currículo escolar. Através de seu discurso, e considerando sua afirmação que não se sente apto para lecionar esses conteúdos, infere-se que suas dificuldades advêm de sua formação, pois não consegue ensinar devido ao caráter matemático dos temas, evidenciando que esse problema também foi enfrentado na graduação, e depende de propostas externas que abordem outros aspectos da FMC.

Dando continuidade, foi pedida aos professores sua opinião sobre a necessidade de novas metodologias para ensinar FMC no EM. Doze afirmaram que sim e apenas dois que não. O Quadro 4 contém suas justificativas.

Quadro 4: Novas metodologias para ensinar FMC no EM.

\begin{tabular}{|c|c|l|}
\hline Professor & Respostas & \multicolumn{1}{c|}{ Justificativas } \\
\hline A & Sim & Formas diversas de abordar os conteúdos sempre terão bons frutos de aprendizagem \\
\hline C & Sim & Para adequar o conteúdo para os alunos \\
\hline D & Sim & A estrutura para esse conteúdo é péssima \\
\hline E & Sim & É necessária uma reformulação no Ensino Médio como um todo \\
\hline F & Sim & É necessário que o aluno escute, leia, mas que também veja e se possível experimente o objeto de estudo \\
\hline G & Sim & Novas metodologias sempre devem ser inseridas, buscando associar o máximo com a vivência dos discentes \\
\hline H & Não & Porque as metodologias usadas hoje podem satisfazer as necessidades dos tópicos de Física Moderna \\
\hline I & Sim & \\
\hline J & Sim & $\begin{array}{l}\text { Alunos com pouco interesse nas disciplinas de Ciências da Natureza (principalmente as que envolvem } \\
\text { cálculos) }\end{array}$ \\
\hline K & Não & \\
\hline L & Sim & \\
\hline M & Sim & Reduzir o nível de abstração \\
\hline N & Sim & As atuais são arcaicas e fora da realidade de ensino \\
\hline O & Sim & Para repassar o conteúdo ao aluno com mais dinâmica, no intuito de chamar atenção. \\
\hline
\end{tabular}

Fonte: Dados da Pesquisa, 2019.

No quadro acima, chama-se atenção para as justificativas docentes para a necessidade ou não de novas metodologias para inserir conteúdos de FMC em suas aulas no EM.

Constata-se que a necessidade de novas metodologias para o ensino de FMC no EM é enfatizada por quase todos os professores, as quais precisam reduzir o nível de abstração desses temas, despertar o interesse dos alunos, possibilitar que experimentem o conteúdo, 
adequar ao nível mencionado, dentre outros motivos ressaltados pelos docentes. É interessante citar ainda a fala do professor E, que ressalta uma necessidade de reformulação do EM. Infere-se que tal reestruturação seja além de metodologias, englobando também uma maior inserção de FMC.

Parece ser geral a carência docente por novas metodologias, o que reforça as pesquisas que apontam a necessidade de trabalhos que elaborem propostas didáticas para esses temas. Para Oliveira, Vianna \& Gerbassi (2007, p. 449), “o caráter formativo desses tópicos deve ser priorizado e faz-se necessário buscar propostas que fujam da mera informalidade do assunto, a fim de que não sejam inseridos como pontos isolados em um currículo que já é bastante extenso". Ferreira \& Strieder (2012) constataram em sua pesquisa que as metodologias são conhecidas pelos professores, entretanto, falta aplicá-las a esses temas, os que reivindica um trabalho suplementar de pesquisa e prática, que poucos fazem no dia a dia. Para os autores, a introdução de tópicos de FMC demanda cuidados com sua abordagem, tendo que o professor estar atentado aos limites do saber de cada aluno. Sugerem que uma boa forma de conseguir englobar todos seria utilizar os limites da própria FC, remetendo ao que já vem sendo ensinado nas escolas tradicionalmente, pois a FC no dia a dia aproxima a abordagem da realidade do estudante, mostrando-se como uma ótima oportunidade para a abordar FMC, além de não deixar de trabalhar os fatos históricos da Ciência na construção da abordagem para situar o conhecimento no tempo. Adicionam ainda que

[...] um pouco mais pode ser feito pelos professores para trazer até o aluno discussões que estejam mais próximas do desenvolvimento tecnológico atual. Como por exemplo: consultar grandes bibliotecas, solicitar leituras científicas além do livro texto, preparar planilhas Excel com cálculos em estudo, preparar atrativas aulas com movimento no Power Point. Todos esses métodos despertam o interesse do aluno para o aprendizado, além de terem custo baixo (Ferreira \& Strieder, 2012, p. 6).

Ostermann \& Moreira (2001) ressaltam que a preocupação de como ou o que usar para alcançar seus objetivos tem que ser a última etapa que o professor deve se preocupar. No entanto, não deve ser negligenciada. Precisam avaliar a metodologia adequada ao nível de conhecimentos de seus estudantes, bem como escolhê-la de acordo com o conteúdo que for ministrar. Dessa forma, serão cada vez mais envolvidos com a educação. Ferreira \& Strieder (2012) perceberam ainda que alguns professores optam pelo livro como base para suas aulas. No entanto, é inviável achar que não se pode lecionar FMC sem outras fontes de informações.

Monteiro \& Nardi (2007) concluem que é preciso propiciar aos professores em formação a autonomia requerida para a tomada de decisões, tanto em termos do ensino de 
(CC BY 4.0) | ISSN 2525-3409 | DOI: http://dx.doi.org/10.33448/rsd-v9i7.4748

conteúdos em si, como também em relação às suas estratégias de ensino, considerando-se estarem desarticuladas entre si. Essa atitude demanda mudanças radicais na estruturação do currículo e nas próprias concepções e ações dos docentes que formam professores de Física. Sobre a atualização curricular, Ostermann \& Moreira (2001) enfatizam que ainda é necessário elaborar mais materiais acessíveis aos professores e ligados aos cursos de formação inicial e continuada.

$\mathrm{Na}$ sexta questão perguntou-se aos professores se eles tiveram dificuldades em aprender FMC durante a graduação. Sete docentes afirmaram que sim e oito afirmaram que não. As suas justificativas para suas dificuldades se encontram no Quadro 5.

Quadro 5: Dificuldades dos professores em aprender FMC durante a graduação.

\begin{tabular}{|c|l|}
\hline Professor & \multicolumn{1}{|c|}{ Justificativa } \\
\hline A & A nova linguagem matemática \\
\hline B & Problemas com a matemática e abstração de experimentos \\
\hline D & Matemática \\
\hline F & A Física Moderna é controversa á Física Clássica estudada durante o curso \\
\hline G & $\begin{array}{l}\text { Na matemática, alguns cálculos complexos, onde não tinha a base } \\
\text { suficiente do Ensino Médio }\end{array}$ \\
\hline L & Os operadores matemáticos são complexos \\
\hline M & Teoria da Relatividade, Mecânica Quântica \\
\hline
\end{tabular}

Fonte: Dados da Pesquisa, 2019.

Percebe-se que suas dificuldades estão relacionadas à Matemática dos assuntos e aos próprios conteúdos em si, bem como a abstração inerente à FMC e a base insuficiente antes de entrar na graduação. Além disso, relacionam-se também com as justificativas para alguns docentes não se sentirem completamente aptos a realizarem a inserção de FMC em suas aulas. Dessa forma, uma maior articulação entre o ambiente em que os professores formadores atuam na universidade e a Educação Básica poderia proporcionar a formação de professores capazes de lecionar esses assuntos, somado ao maior esforço daqueles para que essas dificuldades venham a ser superadas. Os professores entrevistados por Miltão \& Alves (2009) relatam aos autores que as deficiências são efeito do próprio modelo do curso. Comentam que esses conteúdos chegaram a ser trabalhados durante as aulas, só de forma muito rápida, sem o destaque necessário para o conhecimento se consolidar. Tal comportamento estabelece um pacto de mediocridade, pois o estudante tem pressa e pouco interesse e o professor, do outro 
(CC BY 4.0) | ISSN 2525-3409 | DOI: http://dx.doi.org/10.33448/rsd-v9i7.4748

lado, quer apenas receber por suas aulas. Os autores salientam o descompromisso por parte dos estudantes, que deveriam requerer mais de seus professores, e desses que necessitariam mostrar maior responsabilidade com a formação dos estudantes.

Monteiro \& Nardi (2009) constataram também no discurso de licenciandos em Física que as abordagens da Mecânica Quântica não contemplavam suas expectativas cognitivas. Alternativas para mudar essa realidade seria trabalhar mais o conteúdo, levar os alunos a pensarem, a discutirem os paradigmas da FMC e a fazerem relações com a FC (Miltão \& Alves, 2009).

$\mathrm{Na}$ sétima questão foi perguntado se essas dificuldades relatadas na questão anterior impedem os professores de ensinar FMC. Os sete docentes que afirmaram anteriormente terem tido dificuldades durante a graduação atestam que essas não os impedem de ensinar esses temas. Suas afirmações são importantes porque revelam que embora tenham tido dificuldades ainda na formação, essas não os impedem de ensinar tais assuntos no EM. Entretanto, apesar de afirmarem que não os impossibilita, é certo que se essas dificuldades não forem tratadas em uma formação continuada ou superadas por si mesmos, alguns tópicos de FMC podem não ser abordados devidamente ou não ser contemplados no EM devido o professor não se sentir seguro para tal.

A oitava questão perguntou qual enfoque teve o ensino de FMC durante a graduação dos professores. O Gráfico 2 mostra suas respostas.

Gráfico 2: Enfoque do ensino de FMC durante a graduação.

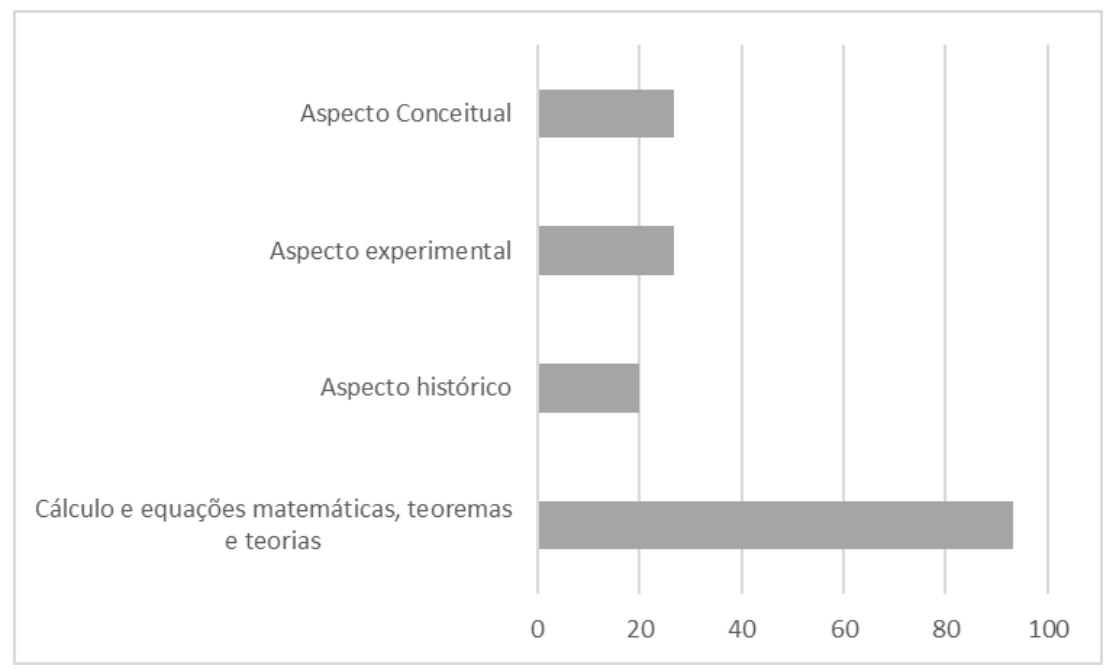

Fonte: Dados da Pesquisa, 2019.

A partir do gráfico, observa-se que a quase totalidade dos professores afirma que o aspecto matemático da FMC foi o que teve maior ênfase durante sua formação, reforçando a 
tradicionalidade do ensino de Física. $\mathrm{O}$ destaque para os cálculos matemáticos acarreta dificuldade nos professores de levar para seus estudantes outros aspectos desses conteúdos, pois não experienciaram durante a graduação. Soma-se a isso, o fato de que o nível dos cálculos é maior que no EM e que os próprios docentes têm dificuldades, podendo ser um dos obstáculos para os docentes apropriarem ao nível dos alunos.

Buscando verificar convergências ou divergências, a questão seguinte questionava os dez professores, que na segunda questão afirmaram inserir FMC em suas aulas no EM, qual enfoque dão. O Gráfico 3 mostra suas respostas.

Gráfico 3: Enfoque das aulas de FMC no EM.

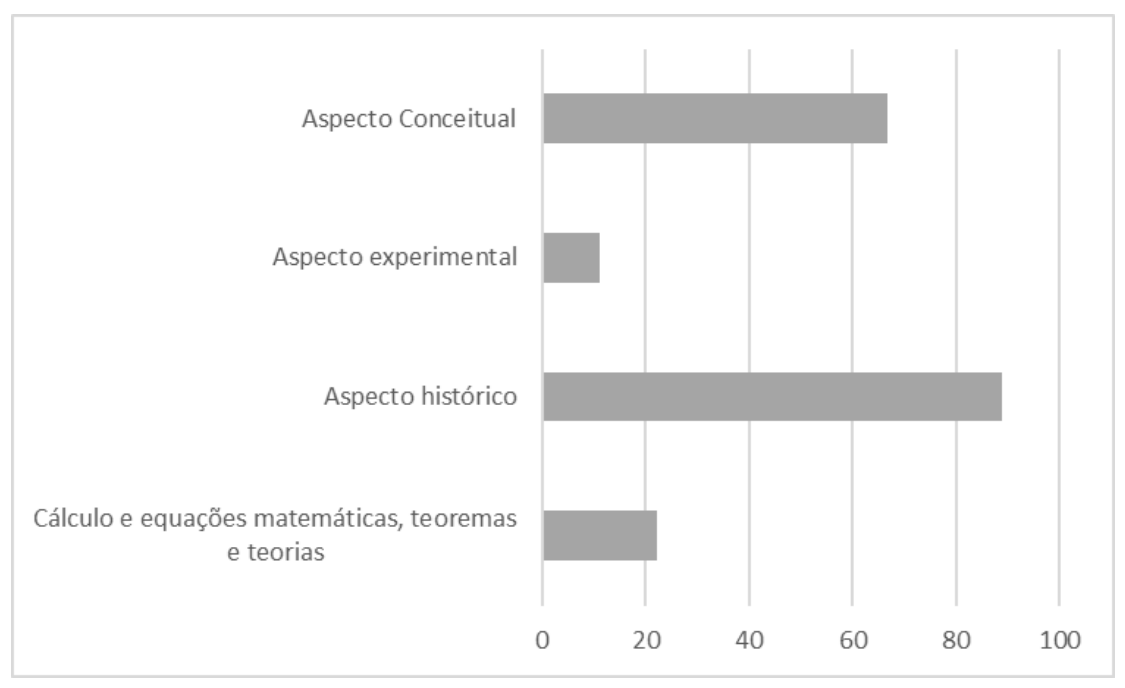

Fonte: Dados da Pesquisa, 2019.

Esse gráfico é importante para que possamos fazer uma comparação com o Gráfico 2, que verificou o enfoque que teve o ensino de FMC na formação inicial dos professores para comparar com o enfoque que tem nas aulas no EM dos mesmos docentes.

Como se pode perceber, comparando os Gráficos 2 e 3, há um contraste muito grande entre aquilo que os professores vivenciaram na faculdade e aquilo que lecionam na Educação Básica, em se tratando de maneiras de se abordar um conteúdo de Física. Portanto, esse fato clama por uma readequação do ensino de FMC no ensino superior, pois os professores de Física em formação precisam ser instruídos a trabalhar esse assunto de outras formas que não sejam os cálculos matemáticos, visto que não podem replicar isso no EM. Dessa forma, terão melhor capacidade e habilidade de inserir de forma eficaz conteúdos de FMC nesse nível.

É muito importante que durante sua formação os professores de Física vivenciem os aspectos epistemológicos e ontológicos da FMC e os vários outros que têm definido a sua 
construção, bem como as implicações desses temas nas várias outras áreas. Dessa forma, é possível que o desempenho do professor esteja em concordância com as perspectivas da ação comunicativa e da ação dialógica, tendo em conta que requerem que a realidade concreta dos participantes seja considerada nos processos educativos (Monteiro, Nardi, \& Bastos Filho, 2012).

Em seguida foi questionado aos docentes se eles consideram que obterão êxito se ensinar FMC no EM da mesma forma que aprenderam durante a graduação. Doze professores afirmaram que não e três que sim. Suas justificativas encontram-se no Quadro 6.

Quadro 6: Justificativas para êxito em ensinar FMC no EM como na graduação.

\begin{tabular}{|c|c|c|}
\hline Professor & Respostas & Justificativas \\
\hline $\mathrm{A}$ & Não & $\begin{array}{l}\text { Abordagem calculista e profundas discussões matemáticas afasta os } \\
\text { estudantes do Ensino Médio da aprendizagem }\end{array}$ \\
\hline B & Não & $\begin{array}{l}\text { Porque é preciso explorar o assunto com a vasta aplicação que ele } \\
\text { possui }\end{array}$ \\
\hline C & Não & $\begin{array}{l}\text { Devido a fragilidade de conhecimentos que o aluno traz ao longo da } \\
\text { sua vida acadêmica }\end{array}$ \\
\hline $\mathrm{D}$ & Não & Outros "tempos". A metodologia deve ser outra \\
\hline $\mathrm{E}$ & Não & $\begin{array}{l}\text { Aulas puramente teóricas tendem a não despertar o interesse dos } \\
\text { alunos }\end{array}$ \\
\hline $\mathrm{F}$ & Não & $\begin{array}{l}\text { As equações utilizadas na graduação não são apropriadas ao nível } \\
\text { médio. O importante é que os alunos tenham noções do que é Física } \\
\text { Moderna }\end{array}$ \\
\hline G & Sim & Sempre busco as melhores formas de associar com o dia a dia \\
\hline $\mathrm{H}$ & Sim & Porque tive, naquilo que fui instruído, uma formação sólida \\
\hline I & Sim & Buscarei inovação, aplicação no cotidiano \\
\hline $\mathrm{J}$ & Não & $\begin{array}{l}\text { O nível é bem avançado em comparação aos alunos do nível médio } \\
\text { (nível de aprendizagem) }\end{array}$ \\
\hline $\mathrm{K}$ & Não & $\begin{array}{l}\text { Porque a Física Moderna na graduação que cursa é muito complexa } \\
\text { matematicamente e eles não iriam acompanhar devido a deficiência } \\
\text { dos alunos das escolas públicas em Matemática }\end{array}$ \\
\hline $\mathrm{L}$ & Não & $\begin{array}{l}\text { Não se pode comparar alguém que escolheu fazer Física dentre todas } \\
\text { as outras áreas }\end{array}$ \\
\hline M & Não & $\begin{array}{l}\text { No Ensino Médio buscamos sempre abordar os tópicos buscando a } \\
\text { aplicabilidade na sua realidade, evitando muitas vezes excesso de } \\
\text { cálculos para assim não afastar aqueles que tenham dificuldades em } \\
\text { Matemática }\end{array}$ \\
\hline $\mathrm{N}$ & Não & $\begin{array}{l}\text { A maturidade dos meus alunos não é suficiente para entenderem o } \\
\text { aprendizado da Física Clássica, imagina da Física Moderna }\end{array}$ \\
\hline $\mathrm{O}$ & Não & Falta um conhecimento básico para uma maioria de alunos \\
\hline
\end{tabular}

Fonte: Dados da Pesquisa, 2019.

O Quadro 6 chama atenção para as justificativas docentes para suas respostas se a repetição da forma que aprenderam tópicos de FMC durante sua formação inicial terá êxito em suas aulas no EM. 
Observa-se que a formação dos professores entrevistados não contribuiu no sentido que pudessem reproduzir suas experiências no EM, evidenciando, novamente, que a formação de professores de Física não tem preparado os profissionais bem informados sobre a realidade do contexto em que estão inseridos. Relatam que a forte ênfase matemática e a necessidade de explorar outros aspectos desses temas se mostram como os principais motivos para que os professores não ensinem FMC como viram na graduação. Outro ponto ressaltado pelos sujeitos foram as dificuldades que os alunos chegam no EM, onde os docentes não conseguem ensinar satisfatoriamente nem a FC. Monteiro, Nardi e Bastos Filho (2009) investigando os processos formativos de professores de Física, corroboram a afirmação dos docentes dessa pesquisa de que não é possível lecionar FMC do mesmo modo que aprenderam durante a graduação. Por mesmo modo refere-se aos mesmos enfoques, mesmas metodologias e mesmas discussões, ou seja, questões relacionadas ao ensino, pois, certamente, o nível de graduação e EM é bem diferente.

Um professor relata aos autores que as aulas de FMC eram sempre expositivas, utilizando-se do quadro em excesso e, empregando muitas equações e definições. A explicação também é sentida pelo sujeito, pois por mais que o professor soubesse o assunto, tinha dificuldade em transmiti-lo, sendo os conceitos totalmente abstratos. Os autores reiteram que as aulas priorizavam o formalismo matemático, com ausência das considerações epistemológicas e ontológicas implícitas ao objeto do conhecimento. Outro docente também relata que o ensino de uma disciplina de FMC foi fortemente pautado na ênfase matemática do conteúdo, sem que houvesse um entendimento conceitual por parte dos alunos.

Foi perguntado aos professores se durante sua graduação eles foram incentivados a inserir FMC no EM. Doze afirmaram que não e apenas dois que sim, os quais relatam: "Vendo a relevância deste tema para o desenvolvimento científico e tecnológico" (professor F); “Abordando assuntos diversos no conteúdo dado em sala de aula, sempre buscando aplicação no cotidiano" (professor I).

Portanto, observa-se que a formação de professores de Física em FMC não tem sido eficiente no sentido de promover a introdução desses temas no EM, visto que quase todos os sujeitos relatam que não houve discussão de como poderiam estar inserindo tais assuntos nesse nível. Esse comportamento colabora para que os professores não realizem essa inserção, posto que não se instruiram sobre como realizar essa ação. Somam-se a isso, as dificuldades e o enfoque que tiveram esses temas durante a graduação, corroborando também para que a FMC não seja inserida em suas aulas. Monteiro, Nardi e Bastos Filho (2009) constataram em sua pesquisa que os professores formadores não discutiram as possibilidades de que a FMC 
fosse introduzida no EM nas futuras aulas dos professores em formação. Monteiro e Nardi (2009) enfatizam que a falta de conhecimento sobre referenciais teóricos relativos à introdução da FMC no EM faz com que o ensino desses assuntos venha perdendo a relevância no contexto em que os professores estão construindo sua formação, em oposição ao que as pesquisas sugerem. Defendem que a inserção de FMC no EM deveria ser discutida ao longo de todo o curso e em várias componentes curriculares, não se restringindo a momentos pontuais ou à componentes curriculares relacionadas com os conceitos específicas.

Orlandi (2002) aponta que atribuir à área pedagógica e à educação o papel de apresentar técnicas de abordagem de FMC para estudantes do EM perpassa uma voz sem nome e é corroborado por Monteiro, Nardi e Bastos Filho (2009) quando afirmam que traz as marcas de uma matriz curricular ainda estruturada em disciplinas de conteúdos específicos e pedagógicos, os quais são desenvolvidos com abordagens e propósitos diferentes e incorporam uma visão de currículo ainda interposto pelo modelo " $3+1$ ".

Desse modo, o sujeito do conhecimento não é o foco dos professores formadores e essa postura confronta a concepção freireana de que ensinar não é transferir conhecimento, e sim criar possibilidades à sua construção pelos envolvidos nas interações de ensino e aprendizagem. Portanto, para se trabalhar na concepção da construção do conhecimento, é necessário haver interação dialógica entre os participantes do contexto educacional, respeitando-se a condição de cada participante (Freire, 2006).

Monteiro, Nardi \& Bastos Filho (2012) apontam que uma evidência do predomínio dos preceitos da racionalidade técnico-instrumental na formação dos professores se mostra acentuada pela ausência de abordagens sobre a introdução da FMC no EM, apesar desses conteúdos serem contemplados nas componentes curriculares durante a formação dos professores. Os autores questionam

[...] até que ponto os demais cursos de formação de professores de Física estão trabalhando a FMC em uma perspectiva que possibilite ao futuro professor introduzir aquela na educação básica, em uma perspectiva crítica em relação à ciência, à tecnologia, bem como quais as consequências sociais delas. Até que ponto as universidades, enquanto espaços de formação e difusão do saber, estão possibilitando que os professores de Física em exercício reelaborem seus saberes acerca do ensino da FMC e conduzam suas práticas em uma perspectiva dialógica? Para a FMC adentrar as salas de aula da educação básica, certamente faz-se necessário que os pesquisadores considerem as reais condições dos professores da educação básica, [...], como também a própria estrutura curricular dos cursos de formação distanciem-se da racionalidade técnica (Monteiro, Nardi, \& Bastos Filho, 2012, p. 157). 
Research, Society and Development, v. 9, n. 7, e749974748, 2020

(CC BY 4.0) | ISSN 2525-3409 | DOI: http://dx.doi.org/10.33448/rsd-v9i7.4748

Concluem que em um curso de formação de professores de Física, embora haja componentes curriculares contemplando FMC, a ausência da abordagem desses conteúdos no EM revela que as práticas dos professores formadores e elaboradores do currículo não estão sendo influenciadas pelas vozes dos pesquisadores da educação científica, muito menos pelos documentos oficiais brasileiros (Monteiro, Nardi, \& Bastos Filho, 2012).

A décima segunda questão tencionava saber quais conceitos de FMC os professores já abordaram em suas aulas no EM. O Gráfico 4 mostra os percentuais de professores para os respectivos conceitos.

Gráfico 4: Tópicos de FMC já abordados pelos professores no EM

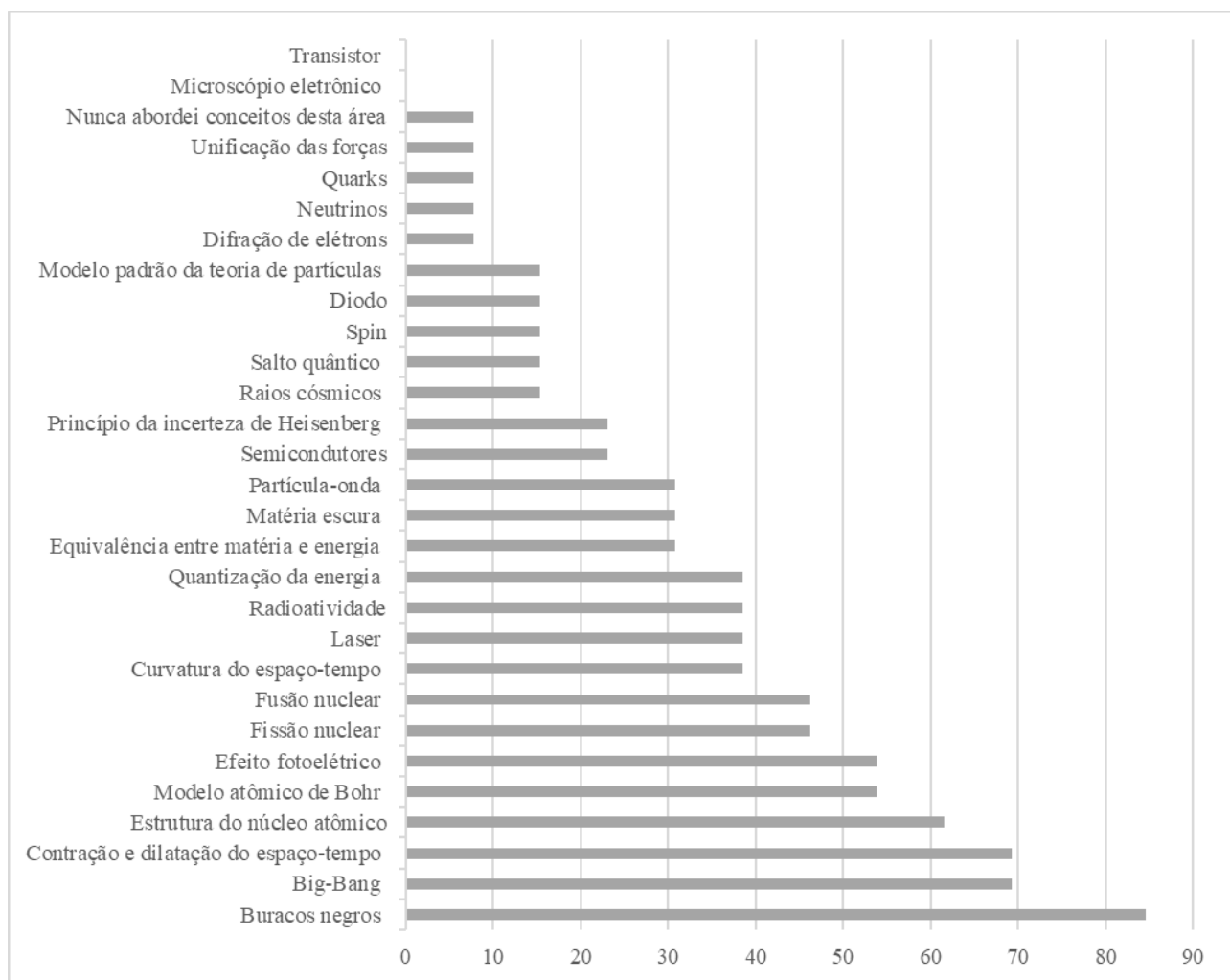

Fonte: Dados da Pesquisa, 2019.

Através do gráfico observa-se apenas dois tópicos de FMC não foram abordados por nenhum dos professores questionados. Infere-se ainda que Buracos Negros, Big-Bang, Contração e Dilatação do espaço-tempo, Estrutura do Núcleo Atômico, Modelo atômico de Bohr e Efeito Fotoelétrico são os conteúdos que mais tiveram espaço nas aulas dos docentes. Embora os outros tópicos tenham sido menos apontados, é importante que alguns professores tenham lecionado, o que mostra que a FMC está no EM, mesmo que não seja igualmente a FC. Um pouco diferente desses resultados, Machado e Nardi (2003) relatam em sua pesquisa 
que os tópicos de FMC mais abordados pelos professores foram: Big-Bang (50\%), Fissão Nuclear (42\%); Fusão Nuclear (42\%), Buracos Negros (33\%); Radioatividade (37\%); Semicondutores (37\%); Transistor (37\%); Equivalência entre matéria e energia (33\%) e Laser (33\%). Renner e Krueger (2016) verificaram que os temas Condutores e Isolantes, Relatividade, Fissão e Fusão Nuclear foram os mais trabalhados pelos professores estudados, bem como os tópicos Efeito Fotoelétrico, Modelo Atômico de Bohr e Dualidade OndaPartícula foram pouco explorados. Dessa forma, infere-se que cada contexto escolar resultará em tópicos diferentes e isso se justifica pelo não estabelecimento dos conteúdos de FMC que devem estar no currículo do EM e o não consenso entre os autores dos livros didáticos sobre quais temas conterão suas obras. Esse fato deixa o professor à mercê de uma orientação sobre o que ensinar de FMC, bem como outros aspectos relacionados ao ensino, acarretando essa disparidade nas respostas dos sujeitos.

Ferreira e Strieder (2012) citam que embora seja impossível criar uma lista definitiva dos conteúdos de FMC, é certo que há a necessidade de se trabalhar todos eles em sala de aula, levando o professor a pensar na possibilidade de superar suas próprias exigências para construir aulas com o que dispõe.

Em seguida, os docentes foram questionados sua avaliação acerca do grau de interesse dos alunos de modo geral pelas aulas de FMC. O Gráfico 5 traz suas repostas, que variam de nenhum a alto interesse.

Gráfico 5: Interesse dos alunos por aulas de FMC

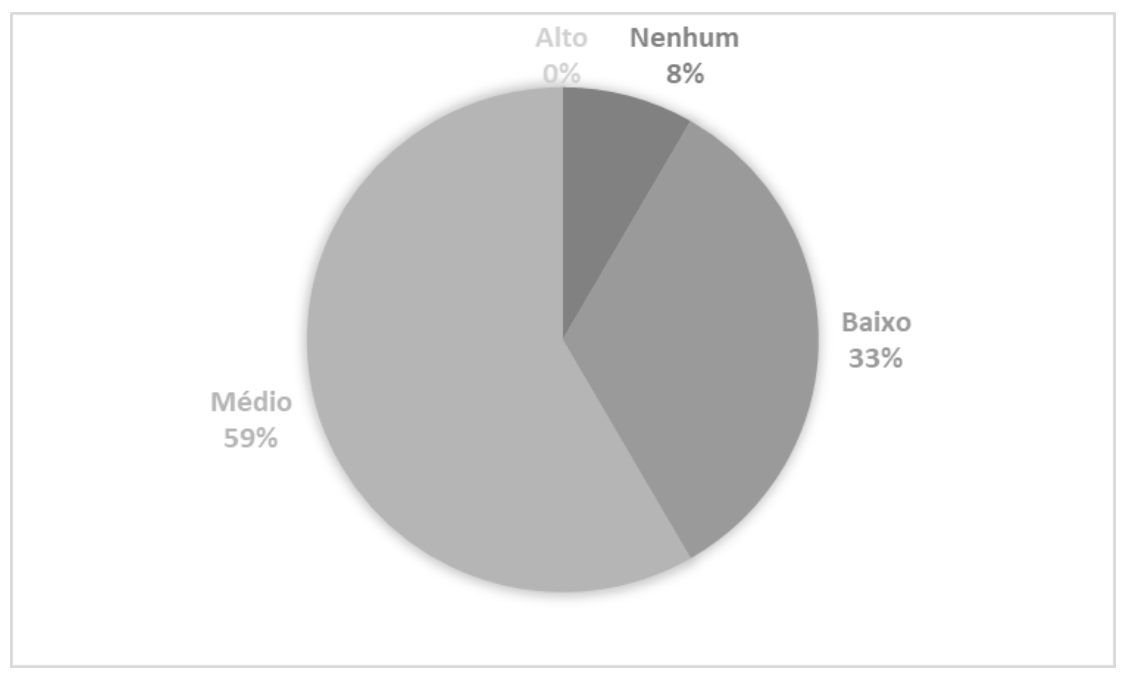

Fonte: Dados da Pesquisa, 2019.

Observa-se que, segundo mais da metade dos professores, o nível de interesse dos alunos por aulas envolvendo conteúdos de FMC é médio. Esse fato levanta questionamentos 
Research, Society and Development, v. 9, n. 7, e749974748, 2020

(CC BY 4.0) | ISSN 2525-3409 | DOI: http://dx.doi.org/10.33448/rsd-v9i7.4748

acerca de quais os motivos que causam esse interesse médio dos estudantes, visto que esses assuntos possuem imensas aplicabilidades e estão muito presentes no cotidiano, além de possuírem uma maior capacidade de chamar a atenção dos alunos quando se compara com os conteúdos abordados na FC. Os professores entrevistados por Machado e Nardi (2009) revelaram que o nível de interesse dos alunos, de modo geral, pelas aulas de FMC foi considerado alto por $21 \%$ dos professores que abordaram estes temas, médio por $42 \%$ e baixo por $37 \%$. Verifica-se que o maior percentual dos professores também aponta que o interesse dos alunos é médio. Eis a questão: Será essa uma realidade nos diferentes contextos escolares? Ou os conteúdos de FMC não estão sendo estudados de uma forma que contribua para a formação dos estudantes e desperte nesses o interesse pela Física?

$\mathrm{Na}$ décima quarta questão, os professores foram perguntados se acham que os tópicos de FMC podem despertar a curiosidade dos alunos do EM, motivando-os para estudar Física. Doze docentes afirmaram que sim e dois que não. Os professores podiam comentar sobre suas respostas, as quais estão no Quadro 7. 
Research, Society and Development, v. 9, n. 7, e749974748, 2020

(CC BY 4.0) | ISSN 2525-3409 | DOI: http://dx.doi.org/10.33448/rsd-v9i7.4748

Quadro 7: FMC como forma de despertar a curiosidade dos alunos do EM.

\begin{tabular}{|c|c|c|}
\hline Professor & Respostas & Comentário \\
\hline B & Sim & $\begin{array}{l}\text { Porque ela possui uma grande aplicação em fenômenos } \\
\text { cotidianos que passam despercebidos }\end{array}$ \\
\hline $\mathrm{C}$ & Sim & - \\
\hline $\mathrm{D}$ & Sim & São interessantes \\
\hline $\mathrm{E}$ & Sim & $\begin{array}{l}\text { Despertar maior interesse estão permeados em séries e filmes } \\
\text { com os quais têm contato }\end{array}$ \\
\hline $\mathrm{F}$ & Não & $\begin{array}{l}\text { Apesar de ser um tema interessante, os alunos não se } \\
\text { envolvem por acharem difícil de entender }\end{array}$ \\
\hline $\bar{G}$ & Sim & São assuntos atuais \\
\hline $\mathrm{H}$ & Sim & $\begin{array}{l}\text { Porque são tópicos atraentes e bem divulgados, como } \\
\text { Relatividade e Efeito Fotoelétrico, que chama atenção. }\end{array}$ \\
\hline $\mathrm{K}$ & Sim & Porque alguns tópicos mexem muito com a imaginação \\
\hline $\mathrm{I}$ & Sim & - \\
\hline $\mathrm{J}$ & Sim & $\begin{array}{l}\text { Porque eles gostam de coisas novas e que possam ver isso no } \\
\text { dia a dia deles }\end{array}$ \\
\hline $\mathrm{L}$ & Não & $\begin{array}{l}\text { Todo e qualquer conteúdo da Física são fascinantes e podem } \\
\text { despertar o gosto pela Física, depende de como ele é } \\
\text { abordado }\end{array}$ \\
\hline M & Sim & Desde que trabalhados com simulações e experimentos \\
\hline $\mathrm{N}$ & Sim & $\begin{array}{l}\text { Porque tem a parte teórica, porém são poucos que despertam } \\
\text { essa curiosidade. }\end{array}$ \\
\hline $\mathrm{O}$ & Sim & $\begin{array}{l}\text { Por conter conteúdos interessantes que explicam em parte a } \\
\text { formação do Universo }\end{array}$ \\
\hline
\end{tabular}

Fonte: Dados da Pesquisa, 2019.

Conforme o Quadro 7, quase todos os professores afirmam que os conteúdos de FMC podem despertar a curiosidade dos alunos do EM, sendo o fato de serem aplicáveis, interessantes, atuais fazerem os estudantes pensarem mais suas principais justificativas. Sobre os que assinalaram como não, questiona-se sobre quais as metodologias que o professor $\mathrm{F}$ utiliza em suas aulas de FMC que levam os alunos a acharem os conteúdos difíceis, pois por mais que possuam maior abstração, podem ser compreensíveis no EM. Sobre o fato apontado pelo docente L, entende-se que a abordagem adotada nas aulas de Física pode despertar a curiosidade nos alunos, qualquer que seja o assunto. No entanto, a questão ressaltada sobre a 
(CC BY 4.0) | ISSN 2525-3409 | DOI: http://dx.doi.org/10.33448/rsd-v9i7.4748

FMC é que esses assuntos estão cada vez mais presentes no dia a dia dos estudantes (filmes, séries, fenômenos físicos etc.), além de possuírem diversas aplicabilidades.

O fato de um conteúdo despertar a curiosidade do aluno está intimamente ligado ao surgimento de interesse por parte desse, que pode, a partir daí, passar a estudar mais sobre Física. Oliveira, Vianna e Gerbassi (2007, p. 447) comentam que é comum os alunos trazerem para as aulas de Física "discussões sobre assuntos que leram ou ouviram em revistas, jornais e telejornais e que, por serem mais atuais e/ou estarem presentes no seu no dia a dia, despertam neles um interesse em conhecer e entender que princípios físicos explicam dado fenômeno".

Por último, os professores foram perguntados se acham que os tópicos de FMC são importantes para a formação básica dos alunos do EM. Doze professores afirmaram que sim e apenas um que não. O Quadro 8 mostra suas escolhas e justificativas.

Quadro 8: Justificativas sobre a importância da FMC para os alunos do EM.

\begin{tabular}{|c|c|l|}
\hline Professor & Respostas & \multicolumn{1}{c|}{ Justificativas } \\
\hline B & Sim & $\begin{array}{l}\text { Porque tratam de assuntos que permitem compreender um pouco melhor os fenômenos que estão presentes } \\
\text { no nosso dia a dia }\end{array}$ \\
\hline C & Não & \\
\hline D & Sim & Entender a Física atual \\
\hline E & Sim & Na formação como cidadãos e pessoas críticas, para que saibam analisar o mundo que os cercam \\
\hline F & Sim & Os alunos devem saber onde a Física já chegou e quais seus desafios \\
\hline G & Sim & Irão entender melhor o funcionamento de novas tecnologias \\
\hline H & Sim & Porque os alunos devem ter um mínimo de formação \\
\hline I & Sim & \\
\hline J & Sim & Por ser a Física atual e algo abstrato aos olhos dos alunos \\
\hline K & Sim & Pois eles teriam uma melhor formação \\
\hline M & Sim & $\begin{array}{l}\text { Muito das tecnologias necessitam de conhecimentos básicos de FíSICA MODERNA para a compreensão } \\
\text { de seu funcionamento. Além disso, alunos do ensino básico estudam tópicos de Astronomia, assim alguns } \\
\text { destes tópicos fará mais sentido para os discentes se eles conhecerem um pouco sobre a Física Moderna e } \\
\text { Contemporânea }\end{array}$ \\
\hline N & Sim & Eles têm curiosidade, mas os livros que o MEC usa não enfoca esses temas \\
\hline O & Sim & Importante para eles saberem a Física Moderna e se interessarem para estudar a Física Clássica \\
\hline
\end{tabular}

Fonte: Dados da Pesquisa, 2019.

Vários são os motivos que os professores justificam a FMC ser importante para a formação dos alunos do EM, sendo a necessidade de se compreender o estágio atual dos conhecimentos físicos e suas aplicações e implicações o principal motivo. Ferreira e Strieder (2012) reiteram que é muito importante que os professores reconheçam a importância do ensino de FMC para os estudantes desse nível. Machado e Nardi (2003) constataram em sua pesquisa que $50 \%$ dos professores consideraram alto, $25 \%$ médio, $13 \%$ baixo e $4 \%$ nenhum grau de importância ao ensino de FMC no EM, evidenciando que são assuntos considerados importante pela maioria dos professores. Monteiro, Nardi e Bastos Filho (2009) observaram em sua pesquisa também que todos os professores atribuem relevância ao ensino de FMC na Educação Básica. Busatto et al. (2018) verificaram que todos os 50 professores entrevistados 
consideram importante a presença de FMC no EM. Rodrigues, Bezerra e Souza (2018) também concluíram que todos os professores consideram importante ensinar FMC nesse nível, visto que a maioria dos conceitos de Física estão presentes no cotidiano.

Cavalcante (1999) vem afirmar que a difusão desses assuntos pelos professores deve ser considerada muito importante, pois o professor é um agente transformador do contexto social no qual está inserido. O conhecimento científico não deve ser entendido como algo distante e fora da realidade dos estudantes, devendo esse paradigma ser descartado e substituído por uma forma de aprendizagem que leve os estudantes ao gosto pela Ciência. Nessa perspectiva, Miltão e Alves (2009) informam que essa não é uma tarefa fácil para a maioria dos professores, pois os sujeitos enfrentam várias dificuldades, como carga horária excessiva e turmas superlotadas, dificultando o trabalho e o aprendizado.

Visto que grande parte dos professores desta pesquisa julgam importante e consideraram ser possível ensinar FMC e as contribuições das pesquisas aqui citadas, nota-se que com maior empenho dos professores formadores na elucidação desses assuntos no nível superior e com a promoção de debates e realização de pesquisas com foco em estratégias para seu ensino, pode-se obter resultados satisfatórios de aprendizagem no EM.

\section{Considerações Finais}

A pesquisa teve como objetivo principal avaliar as concepções dos professores de Física das escolas públicas de Sobral que concluíram sua graduação após o ano de 2002 acerca do ensino de tópicos de FMC no EM. Além disso, observou-se também outras questões relacionadas ao ensino desses tópicos, como a necessidade de novas metodologias, se os docentes são aptos e inserem esses temas, quais assuntos já foram inclusos em suas aulas e se durante sua formação foram incentivados a realizar essa inserção, bem como sua importância para a formação básica dos estudantes do EM. Para tanto, foi aplicado um questionário semiestruturado a todos os professores, no perfil citado, para coletar os dados.

Percebeu-se que todos os professores são licenciados e consideraram ser possível ensinar FMC no EM, mostrando que reconhecem as possibilidades para essa inserção, cujas justificativas mostram a relevância do assunto para formação básica dos alunos. Para que os professores que assinalaram ser parcialmente possível, constata-se uma forte ênfase para que sejam trabalhados apenas os conceitos da FMC, considerando a maturidade cognitiva dos estudantes frente à matemática requerida. No entanto, é possível abordar também o enfoque 
matemático desses assuntos, com um nível adequado. Não se pode exigir os cálculos do ensino superior, mas também não se pode desvincular a Física da Matemática.

Outro ponto bastante recorrente nos discursos dos professores é o tempo, pois duas aulas semanais é considerado muito pouco para ensinar tudo que orientam os documentos oficiais. Os resultados mostram que uma readequação nos conteúdos possibilitará haver mais assuntos de FMC no currículo. Não se objetiva desmerecer a FC, pois é importante e continua válida, mas uma distribuição harmoniosa entre essas áreas da Física poderia evitar lacunas na formação dos alunos. Além disso, o aumento da carga horária semanal de Física, não apenas porque alguns tópicos podem ser inseridos, aumentando a grade curricular, proporcionaria mais tempo para explorar os conteúdos, o que favoreceria a aprendizagem significativa, e, para isso, é preciso que seja utilizado mais que lousa e pincel. Por último, o currículo e a ausência de tópicos de FMC nos vestibulares também contribuem fortemente que esses assuntos não façam parte das aulas de Física. Não podemos deixar que o currículo prenda os professores, mas que abram janelas para novas oportunidades.

Foi importante perceber que mais da metade dos professores afirmam inserir temas de FMC em suas aulas do EM. No entanto, as justificativas de três docentes para não realizar tal ação mostram que o currículo e os exames de vestibular têm limitado os professores na medida em que norteiam o que deve ser estudado nas escolas, baseados em seus próprios conteúdos programáticos, não, necessariamente, aqueles que contribuem significativamente para a formação do ser crítico. Precisamos formar pessoas coerentes com a realidade em que vivem e capazes de aplicar os conhecimentos aprendidos na escola, não seres alienados que tiveram formações baseadas no norteamento do currículo e dos vestibulares. Dessa forma, uma revisão do currículo escolar poderá trazer mais clareza aos assuntos de FMC e orientar os professores, sem os prender. Outro ponto importante é a inclusão da FMC nos programas de vestibular, não como uma forma de cobrar o ensino desses temas no EM, mas porque se compreenda sua importância no contexto atual.

Constatou-se que, embora $64 \%$ dos docentes considerem-se completamente aptos a ensinar FMC, ainda é necessário que esses professores passem por uma formação continuada para que aprimorem seus conhecimentos. Infere-se que os docentes que afirmam ser parcialmente aptos ou inaptos tendem a não inserir esses temas em suas aulas, pois sua insegurança quanto a esses tópicos e a cobrança externa, currículo e vestibulares, por conteúdos de FC podem levá-los a dar preferência a esses últimos. A deficiência ainda na sua formação e a falta de metodologias são as principais justificativas docentes para não se sentirem totalmente aptos. Soma-se a isso, o professor $\mathrm{N}$ também afirma que a formação de 
professores de Física não tem sido eficiente na medida em que não considera o contexto que os sujeitos, professores e alunos, estão inseridos, pois na graduação é idealizado um EM, mas quando chegam na prática se deparam com outra realidade. Esse docente também relata que não buscou formas de ensinar FMC em suas aulas e justifica como causa as limitações do currículo, mostrando mais uma vez o poder que esse tem de nortear o que deve ou não ser ensinado, não permitindo que o professor enxergue para além dele e veja as diversas possibilidades. Tudo isso só será possível se os professores formadores considerem a necessidade de inserir FMC nesse nível e o contexto dos seus alunos, graduandos, e de seus futuros estudantes do EM.

É quase unanimidade entre os sujeitos que são necessárias novas metodologias para o ensino de FMC no EM, sendo a necessidade de reduzir o grau de abstração dos tópicos, adequação ao nível dos alunos e formas de associação com seu cotidiano os principais pontos nos discursos dos professores. Esse resultado mostra a importância e carência por novas formas de ensinar, novos meios. Portanto, mais pesquisas sobre o ensino de FMC e o desenvolvimento das metodologias requeridas poderão possibilitar que tais temas adentrem nas aulas de Física de uma maneira significativa, que contribua para a formação discente. Sequências de ensino de tópicos de FMC mostram-se como muito importante nesse contexto porque permite aos professores reproduzir e/ou adaptar modelos que foram desenvolvidos para suprir as carências do processo de ensino-aprendizagem.

Sobre as dificuldades nos conteúdos de FMC durante sua formação, $47 \%$ dos professores questionados afirmam que as tiveram, o que releva a necessidade de que se trabalhe mais esses assuntos e se desenvolva metodologias também para a graduação. $\mathrm{O}$ que ensinar, por que ensinar, como ensinar, para quem ensinar, devem ser questões que precisam sempre se fazer presentes no planejamento dos professores, sejam de ensino superior ou EM. $\mathrm{O}$ fato de esses assuntos requererem uma matemática mais aguçada é um dos principais fatores que dificultam sua aprendizagem pelos docentes em sua formação inicial, acompanhado por obstáculos no próprio entendimento de alguns temas. No entanto, nenhum dos sete professores que afirmaram ter tido dificuldades na graduação consideram que essas sejam um impedimento para ensinar FMC no EM. Mesmo assim, é pertinente que tal realidade seja tratada e revertida em cursos de formação continuada de professores.

Quanto ao enfoque que os conteúdos de FMC têm durante a formação de professores, é notório que os cálculos matemáticos se sobressaem frente aos outros, que foram pouco apontados pelos sujeitos. Contrariamente, o enfoque que dão em aulas de FMC no EM é praticamente conceitual e histórico. Visto que os professores tiveram sua formação em FMC 
pautada no aspecto matemático, esse fato gera dificuldades de abordar esses assuntos de outras maneiras, podendo fazê-lo de forma "incorreta", sem obter êxito. É importante que tanto os professores em formação quanto os alunos do EM tenham contato com os diferentes vieses que o ensino de Física pode tomar, pois precisam, urgentemente, entender que é para além da Matemática.

$\mathrm{O}$ fato de quase todos os professores considerarem que não obteriam êxito se lecionassem FMC da mesma forma que aprenderam durante sua graduação mostra que a formação de professores não tem contribuído para que esses "reproduzam", no nível adequado, os conhecimentos aprendidos. Não é apenas “jogar” conteúdos nos alunos e esperar que aprendam, mas ensiná-los e mostrá-los como pode ser aplicado no EM, utilizando os diversos aspectos que a Física possui. Ou seja, realizar a Transposição Didática.

Constatou-se que quase todos os tópicos de FMC postos no questionário foram assinalados pelos professores, apenas dois não o foram. O que se sobressaíram foram: Buracos Negros, Big-Bang, Contração e Dilatação do espaço-tempo e Estrutura do Núcleo Atômico. Isso mostra que a FMC está, mesmo que não satisfatoriamente, inclusa nas aulas de Física do EM, o que revela um certo empenho dos professores em incluir esses temas transversalmente nas aulas de FC. É inviável elaborar uma lista com os mais citados pelas diversas pesquisas, pois cada contexto resulta em uma realidade diferente. É necessário que os pesquisadores e elaboradores do currículo estudem e estabeleçam, junto à comunidade de autores de livros didáticos, os tópicos que devem estar presentes no EM, de forma que não prejudiquem a formação dos alunos e contribuam para que possam compreender a Física como um empreendimento humano e aplicada ao cotidiano.

É ciência entre grande parte dos professores de que os conteúdos de FMC são capazes de despertar a curiosidade dos alunos EM, motivando-os a estudar mais Física. As principais justificativas apontadas são o fato de os temas serem interessantes e poder fazer diversos links com o cotidiano dos estudantes, mostrando-os as aplicações e enfatizando a importância e necessidade de que os compreendam. É certo que os tópicos de FMC necessitam de uma compreensão mais profunda para que se possa captar sua essência, no entanto, se trabalhados de forma correta, podem ser perfeitamente aplicáveis no EM, contrapondo ao exposto pelo professor $\mathrm{F}$ quando ressalta que os alunos não se envolvem por acharem difícil. O achar difícil é uma predisposição para que eles não se envolvam, porém, questiona-se como o professor abordou esses conteúdos, quais enfoques utilizou, quais metodologias etc. A forma com que a Física é ensinada é que causa o despertar de interesse ou não por parte dos alunos, conforme 
assinala o professor L. Sobre os temas de FMC, o que se discute é que suas aplicabilidades e necessidades cognitivas se diferenciam dos outros conteúdos.

Quase todos os docentes afirmaram considerar que o ensino de FMC é importante para formação básica dos alunos do EM, mostrando-se como um fator positivo, e justificam que esses temas contribuem para a construção do ser crítico, capaz de pensar e agir sobre o mundo que o cerca, e para que os estudantes possam compreender as diversas aplicações que possuem. Um ponto muito importante é a necessidade de rever quais e como os conteúdos de FMC são apresentados nos livros didáticos, pois, considerando sua importância, é preciso que contemplem esses assuntos de maneira que contribua como o processo de ensinoaprendizagem dos estudantes, para que, desse modo, comentários como o do professor $\mathrm{N}$ sobre os livros adotados pelo MEC não focarem nesses temas não seja mais realidade.

Mais da metade dos professores atribuiu que o interesse dos alunos pelas aulas envolvendo temas de FMC é médio e nenhum atribui alto. Dessa forma, considerando a importância que os professores atribuíram e que é defendida pelas pesquisas na área, bem como as diversas aplicações que possuem no campo das novas tecnologias, questiona-se o porquê desse interesse médio, pois com tantas investigações acerca dessa problemática e defesa desses tópicos no EM, o que se espera é que os alunos achem as aulas de FMC interessantes.

Considerando o caminho trilhado pela pesquisa, abrem-se possibilidades para novas investigações que venham a contribuir e sanar os questionamentos gerados no presente trabalho. Nesse interim, parece conveniente:

- Analisar até que ponto o currículo tem contribuído para o processo de ensinoaprendizagem e influenciado os conteúdos nas aulas de Física, atentando para seu controle nas ações pedagógicas dos professores;

- Investigar detalhadamente a influência do ensino de temas de FMC durante a graduação na capacidade dos professores em lecioná-los no EM, propondo formas de reverter as dificuldades que enfrentam para realizar tal ação;

- Estudar as necessidades docentes e apresentar metodologias que possam suprir suas carências para ensinarem FMC no EM;

- Pesquisar quais motivos estão envolvidos no interesse médio atribuído pelos alunos, segundo os professores, às aulas envolvendo conteúdos de FMC;

- Ouvir os docentes que lecionam as disciplinas de FMC dos cursos de formação de professores de Física para saber suas visões acerca da inserção desses temas no EM, 
investigando se o ensino desses conteúdos também é trabalhado em uma perspectiva que possibilite os professores em formação futuramente incluí-los em suas aulas.

\section{Referências}

Bogdan, R. C., \& Biklen, S. K. (1994). Investigação Qualitativa em Educação: Uma Introdução à Teoria e aos Métodos. Portugal: Porto Editora.

BRASIL (2002). Orientações Curriculares para o Ensino Médio: Ciências da natureza, matemática e suas tecnologias. Brasília: Secretaria de Educação Básica.

Busatto, C. Z., Silva, J. C. da R., Pansera Junior, N., \& Pérez, C. A. S. (2018). O ensino de física moderna e contemporânea na educação básica: conteúdos trabalhados pelos docentes. Revista CIATEC, 10(1), 104-115.

Camargo, S., \& Nardi, R. (2005). A formação inicial de professores de Física: discursos de licenciandos sobre a prática docente. Anais do Congreso Internacional sobre investigación en la didáctica de las Ciências: educación científica para la ciudadanía. Granada: BURGOS, Espanha, 7.

Carvalho, S. H. M. de, \& Zanetic, J. (2004). Ciência e arte, razão e imaginação: complementos necessários à compreensão da física moderna. Atas do Encontro de Pesquisadores em Ensino de Física. Jaboticatubas, MG, Brasil, 9.

Cavalcante, M. A. (1999). O Ensino de uma Nova Física e o Exercício da Cidadania. Revista Brasileira de Ensino de Física, 21(4), 550-551.

Ferreira, A. R., \& Strieder, R. B. (2012) Compreensões de professores e licenciandos com relação à abordagem da Física Moderna e Contemporânea no Ensino Médio. (Trabalho de Conclusão de Curso - Curso de Física). Universidade Católica de Brasília, Brasília.

Fonseca, J. J. S. da. (2002). Metodologia da pesquisa científica. Apostila. Fortaleza: UEC.

Freire, P. (1983). Extensão ou comunicação? (8a ed.). Rio de Janeiro: Paz e Terra. 
Gil, A. C. (2008). Métodos e Técnicas de Pesquisa Social (6a ed.). São Paulo: Editora Atlas.

Machado, D. I., \& Nardi, R. (2003). Avaliação do ensino e aprendizagem de física moderna e contemporânea no ensino médio. Anais do Encontro Nacional de Pesquisa em Educação em Ciências. Bauru, SP, Brasil, 4.

Miltão, M. S. R., \& A, Y. de M. (2009). Formação de professores de física, modalidade presencial da UEFS, e física moderna e contemporânea. Atas do Simpósio Nacional de Ensino de Física. Vitória, ES, Brasil, 18.

Monteiro, M. A., \& Nardi, R. (2009). A Física Moderna e Contemporânea no Ensino Médio e a Formação de Professores: racionalidade técnica ou racionalidade comunicativa?. Atas do Simpósio Nacional de Ensino de Física. Vitória, ES, Brasil, 18.

Monteiro, M. A., Nardi, R., \& Bastos Filho, J. B. (2009). Dificuldades dos professores em introduzir a física moderna no ensino médio: a necessidade de superação da racionalidade técnica nos processos formativos. In R. Nardi. (Org.), Ensino de ciências e matemática, I: temas sobre a formação de professores [online] (145-159). São Paulo, SP: Editora UNESP.

Monteiro, M. A., Nardi, R., \& Bastos Filho, J. B. (2012). Física Moderna e Contemporânea no ensino médio e a formação de professores: desencontros com a ação comunicativa e a ação dialógica emancipatória. Revista Electrónica de Investigación en Educación en Ciencias, $8(1), 1-13$.

Oliveira, F. F. de, Vianna D. M., \& Gerbassi, R. S. (2007). Física Moderna no ensino médio: o que dizem os professores. Revista Brasileira de Ensino de Física, 29(3), 447-454.

Orlandi, E. P. (2002). Análise de discurso: Princípios e Procedimentos (4a ed.). Campinas: Pontes.

Ostermann, F., \& Moreira, M. A. (2001). Atualização do currículo de física na escola de nível médio: um estudo dessa problemática na perspectiva de uma experiência em sala de aula e da formação inicial de professores. Caderno Catarinense de Ensino de Física, 18(2), 135-151. 
Paulo Neto, J. G., Oliveira A. N. de, \& Siqueira, M. C. A. (2019). Ensino de Física moderna e contemporânea no Ensino Médio: o que pensam os envolvidos? ScientiaTec: Revista de Educação, Ciência e Tecnologia do IFRS, 6(1), 65-89.

Renner, G. L. P., \& Krueger, C. (2016). Física Moderna e Contemporânea no Ensino Médio: Um estudo acerca dos fatores que interferem na aplicação dos conceitos relacionados em sala de aula. Atas do Simpósio Nacional de Ensino de Ciências e Tecnologia. Ponta Grossa, PN, Brasil, 5.

Rocha, D. M., \& Ricardo, E. C. (2011) Crenças de Autoeficácia e a Formação Docente em Física Moderna e Contemporânea: uma relação atuante nas práticas dos professores. Anais do Encontro Nacional de Pesquisa em Educação em Ciências, Campinas, SP, Brasil, 8.

Rodrigues, E. da S., Bezerra, D. de O., \& Souza, C. J. de M. (2018). Análise das propostas de inserção de física moderna e contemporânea e sua viabilidade de aplicação no ensino médio do sertão central pernambucano. C\&D-Revista Eletrônica da FAINOR, 11(1), 144-173.

Rosa, M. I. de F. P. dos S., \& Schnetzler, R. P. (2003). A Investigação-Ação na Formação Continuada de Professores de Ciências. Ciência \& Educação, 9(1), 27-39.

Siqueira, M., \& Pietrocola, M. (2006). A Transposição Didática aplicada a Teoria Contemporânea: a Física de Partículas Elementares no Ensino Médio. Anais do Encontro Nacional de Pesquisa em Ensino de Física, Londrina, PR, Brasil, 10.

Zanetic, J. (2005). Física e cultura. Ciência e Cultura, 57(3), 21-24.

\section{Porcentagem de contribuição de cada autor no manuscrito}

Jonas Guimarães Paulo Neto - 50\%

Nórlia Nabuco Parente - 25\%

Diego Ximenes Macedo - 25\% 